\title{
Six Essential Instructional Roles to Implement Response to Intervention Models: Perceptions of Highly Qualified Special Educators
}

\author{
John J. Hoover*, Julia S. Sarris \\ University of Colorado, Boulder \\ *Corresponding author: john.hoover@colorado.edu
}

Received January 14, 2014; Revised January 29, 2014; Accepted April 21, 2014

\begin{abstract}
Survey research was conducted to examine practitioners' reported implementation of key instructional roles in response to intervention (RTI) models. A survey was administered to 65 practitioners who completed a nationally accredited degree program from 2004-2011, resulting in a Masters Degree in Special Education and a state teaching endorsement as a highly qualified K-12 special educator. Research addressed the question: To what extent do practitioners trained as special educators report engaging in six key roles, and associated subskills, in their implementation of an RTI Model? Results suggest that educators trained in special education, working in general or special education settings, engage in implementing each of the key roles within their RTI models. Implications and suggestions for teacher preparation of special educators are provided.
\end{abstract}

Keywords: response to intervention, teacher preparation

Cite This Article: John J. Hoover, and Julia S. Sarris, "Six Essential Instructional Roles to Implement Response to Intervention Models: Perceptions of Highly Qualified Special Educators.” American Journal of Educational Research, vol. 2, no. 5 (2014): 257-266. doi: 10.12691/education-2-5-4.

\section{Introduction}

The Individuals with Disabilities Education Act (IDEA) of 2004 contains language that directly addresses the reality that many struggling students do not receive necessary instructional supports or interventions until after they have exhibited repeated failures in the classroom, often leading to special education. IDEA stresses the need for educators to provide increased supports or early intervention to struggling learners through a contemporary model referred to as Response to Intervention (RTI). RTI models include structures that reduce the 'wait to fail' condition often seen in today's classrooms, by emphasizing early screening and necessary supports for all struggling students in a timely manner (Hall, 2008). An RTI model represents a multi-tier process that includes research-based universal core instruction (Tier 1); evidence-based small group supplemental supports (Tier 2 ); and, intensive interventions for those with more significant instructional needs (Tier 3) (Fuchs \& Fuchs, 2006). An ultimate goal of an RTI model is to reduce the need for special education referrals and subsequent placement by addressing learner needs in a timely and structured manner. Essential components of any RTI model include research-based instruction and interventions, data-based decision making, and universal screening implemented within a series of levels or tiers, within which instruction increases in time and duration based on data scores reflecting progress toward grade level benchmarks. (Fuchs \& Fuchs, 2006; NRCLD 2006).
One outcome from the implementation of an RTI model is seen in the changing roles of various school personnel (Council for Exceptional Children, 2007, 2009; Cummings, Atkins, Allison, \& Cole, 2008; Fuchs \& Deshler, 2007; Hoover \& Patton, 2008; National Association of School Psychologists, 2006). The need to adjust to new or changing roles within an RTI model affects most educators including general class teachers, school psychologists, interventionists, social workers and special educators. In particular, IDEA provides provisions for special educators to work with struggling learners prior to special education placement, in efforts to prevent problems from becoming more significant. Additionally, in any RTI model general educators are faced with the continued challenges of educating students with special needs in their inclusive educational settings. As a result of RTI, contemporary instructional demands require educator reliance on new roles and/or increased emphasis on existing roles to meet the learning needs of all students with special needs. This article summarizes a study designed to gather self-reported perceptions of highly qualified special educators in their implementation of six key roles in RTI models.

\section{Literature Review}

Six educator skill sets necessary for successful implementation of RTI have been discussed in the literature: 1) data-driven decision-making, 2) implementation of evidence-based practice, 3) implementation of socio- 
emotional and behavioral supports, 4) differentiation of instruction, 5) instructional and assessment accommodations, and 6) collaboration (Hoover et al., 2008; Katsiyannis, Zhang, Ryan, \& Jones, 2007; Mitchell, 2011; Orosco, 2004; Palenchar, 2012; Salend, 2010; Swanson, Solis, Ciullo, \& McKenna 2012; Werts, Lambert \& Carpenter, 2009). The significance and literature-based grounding for each of the six skill sets as reflected in essential educator roles are summarized below.

\subsection{Role 1: Data-Driven Decision Maker}

RTI is grounded in the collection and use of data as the basis for instructional and eligibility decision-making (Fuchs \& Fuchs, 2006; Stuart \& Rinaldi, 2009; Vaughn \& Linan-Thompson, 2003). Although the collection and use of data to support decision-making have emerged as critical in an RTI model, Mitchell (2011) found that special educators working as diagnosticians spend only $13 \%$ of their time in this role. This finding highlights an important area of need given that multiple sources of assessment and monitoring of student progress exist in schools and classrooms. To further examine this role from the perspective of classroom teachers or other direct service providers with special education training, thirteen skills for making data-based decisions are incorporated in the project survey, including curriculum-based measurement (Fuchs \& Fuchs, 2006), gap analysis (Colorado Department of Education, 2005), and progress monitoring (Vaughn, 2003).

\subsection{Role 2: Implementer of Evidence-Based Practice}

Implementation of evidence-based practice is an essential foundational element of any RTI model. Evidence-based practice reflects two types of instructional methods important to providing quality instruction: 1) evidence-based interventions, and 2) promising practices. Evidence-based interventions are those methods with a significant number of studies with high quality designs showing causality and meaningful effects on outcomes (Cook \& Cook, 2011). A promising practice is a method with high potential for becoming an evidence-based intervention, grounded in sound theoretical rationale, yet currently lacks extensive research (WICHE Promising Practices Website). Though critical to implementing RTI, Mitchell (2011) found that special educators spend only $27 \%$ of their time using evidence-based practices, even though a variety of interventions have been identified and researched (What Works Clearinghouse Website; Doing What Works Website). Thirty of these practices frequently discussed in the literature were incorporated in the project survey to examine this role. These include Reciprocal Teaching (Palinscar \& Brown, 1984), Language Experience Approach (Allen, 1976), Graphic Organizers (Reading) (Kim, Vaughn, Wanzek, \& Wei, 2004), Cognitive Guided Instruction (Montague \& Dietz, 2009), Peer Assisted Learning Strategies (Fuchs, Fuchs, \& Burish, 2000), Schema-based Instruction (Jitendra, 2008), and Classwide Peer Tutoring (Greenwood, Arreaga-Mayer, Utley, Gavin, \& Terry, 2001).

\subsection{Role 3: Implementer of Socio-Emotional and Behavioral Supports}

A comprehensive RTI model includes a framework that simultaneously addresses both academic and socialemotional/behavioral needs of learners (Alberto and Troutman, 2012; Fisher, Frey \& Thousand, 2003; McConnell, 2001; Sugai, rtinetwork website). A structure to best meet the social-emotional and behavioral needs is reflected in a School-Wide Positive Behavior Support (SWPBS) system (Sugai et al., 2000). In particular, "preventing the development and lessening the intensity of problem behavior must be a high priority of instructors seeking to maximize student learning and the impact of effective interventions" (Sugai, rtinetwork website). A variety of essential skills are necessary to fulfill this role. Fifteen skills documented in part from the above literature sources are incorporated in the project survey, including functional behavioral assessment, self-monitoring, schoolwide behavioral program, and applied behavior analysis.

\subsection{Role 4: Differentiator of Instruction}

Differentiated instruction is an essential cornerstone to effective teaching (Tomlinson \& Imbeau; 2010; Tomlinson; 1999) and is critical to the successful delivery of multi-tiered instruction in an RTI model (Vaughn, 2003). Core, supplemental and intensive instruction must be properly implemented to meet diverse learner needs, and differentiation is central to providing this high quality instruction. A variety of subskills reflecting this important role within RTI are incorporated in the project survey, and include attention to skills reflecting a variety of classroom and instructional factors such as flexible classroom groupings, managing instructional time, ways to meet cultural and linguistic needs, varied curriculum access points, and activation of prior knowledge to name a few (Peterson \& Hittie, 2010; Tomlinson \& Imbeau, 2010).

\subsection{Role 5: Implementer of Instructional/Assessment Accommodations}

Students who struggle to achieve at benchmark often require some instructional and/or assessment accommodations to make adequate progress (Thurlow, Elliott, \& Ysseldyke, 2003). Instructional accommodations assist to provide struggling students with sufficient opportunities to learn, and assessment accommodations provide appropriate opportunities for students to demonstrate their acquired knowledge and skills (Hoover, 2009). Five accommodations are frequently discussed to best meet needs of struggling learners or those with special needs: presentation, time, response mode, scheduling, and setting (Katsiyannis, Zhang, Ryan, \& Jones, 2007; Orosco, 2004; Salend, 2010). Each of these is essential for educators to implement this role in RTI models and is included in the project survey.

\subsection{Role 6: Collaborator}

Educators are required to collaborate frequently to best implement instruction and service delivery within an RTI model (Fisher et al., 2003; Cummings et al., 2008; Stuart \& Rinaldi, 2009). Specifically, collaboration among general educators, special educators, paraprofessionals, administrators, and/or parents is essential to meet diverse needs of all students in various classroom settings (Gravois et al., 2005; Knotek, 2005; Vaughn \& Fuchs, 
2003). Palenchar (2012) validated this role as vital to the successful implementation of RTI, finding that $72 \%$ of respondents indicated that they spent more time collaborating under the RTI model than previously. However, Mitchell (2011) found that special educators spend only $27 \%$ of their time collaborating, which includes tasks such as consulting with students and paraprofessionals and assisting the general educator in the classroom. Several skills are required to successfully implement the role of collaborator. Fifteen key skills were identified from the literature and incorporated in the project survey (Friend \& Cook, 2012; Dettmer, Knackendoffel \& Thurston, 2012; Gay, 2010), including co-teaching, consultation, culturally responsiveness, and peer coaching.

In summary, the literature identifies the significance of each of the six roles to successfully implement RTI for all students, especially struggling learners. Additionally, recent research findings suggest that these six roles may not be implemented as frequently as necessary to deliver RTI for all students. The results from this project add to the body of research at the intersection of special education teacher preparation and the education of special learners within response to intervention models of instruction, by documenting extent to which highly qualified special educators state they assume each role.

\section{Methods}

\subsection{Participants}

A total of 65 special education-endorsed practitioners were included in the project. All educators completed an MA degree and endorsement program in special education at a large research university in a mountain western state in the United States, being prepared as highly qualified special educators meeting state teaching endorsement requirements. This population represented a diverse sample with respondents employed in a variety of different educational positions, working with students who have different disabilities, and possessing varying lengths of time implementing an RTI model. Respondents completed their degree and endorsement program between 2004 and 2011, with 75\% completing the program since 2007.

Fifty-nine percent of respondents teach in grades K-5 and $26 \%$ in grades $6-12$, evenly divided between positions in general and special education. The remaining $15 \%$ of respondents assumed positions primarily as coordinators, supervisors, or administrators. Nearly all respondents (98\%) have worked with a student with a learning disability, as well as students with emotional disorders (57\%), autism (35\%) and intellectual disabilities (35\%). Nearly all respondents (94\%) indicated that they had a high or moderate level of proficiency with RTI models, with most (66\%) having three or more years experience working within an RTI model.

\subsection{Research Question}

This project was designed to answer one primary research question:

To what extent do practitioners trained as special educators report engaging in six key roles, and associated subskills, in their implementation of an RTI Model? A survey was developed, piloted and revised to solicit practitioner responses to 100 subskills grouped within the six roles essential for success with RTI models.

\subsection{Survey}

Based on the review of literature over 100 instructional subskills for the six roles combined were identified and piloted with twelve educators. Item wording for clarification and accuracy was revised based on the feedback from the pilot. The content validity of the survey items is grounded in the extensive literature cited above discussing each role, along with feedback from the pilot. The survey's internal reliability was determined based on the entire project sample of participants, yielding Cronbach's alpha of .97, indicating a highly internally consistent and reliable instrument reflecting literaturebased content valid items.

While not intended to be all-inclusive, these survey subskills represent the most frequently discussed practices, interventions and knowledge topics identified in the literature as essential to implementing the six roles. Additionally, while each instructional subskill was classified within a defined role, the possibility exists that some subkills may appropriately be associated with an additional role (e.g., Functional Behavioral Assessment is an instructional subskill necessary for both Data-Driven Descison Making and Social/Emotional Behavioral Supports). However, since each role has multiple subskills and given that the overall purpose of the survey is to facilitate educators' reported use of each skill area, any overlap across roles will have minimal consequence on educators' perceptions of the six roles. Subjects were asked to identify on a 4-point Likert scale ( 1 = Extensively; 2 = Frequently; 3 = Rarely; 4 = Never) the extent to which they engage in each instructional skill area for the roles. The survey was emailed to subjects using a web-based survey program (i.e., Survey Monkey) in the summer and fall of 2012. Two follow-up emails were sent to encourage responses. All instructional subksills for each role are provided in the tables found in the Results section below.

\section{Results}

An $80 \%$ response rate was obtained $(n=52)$. Responses were collected and means were calculated and analyzed using the web-based survey monkey program, Excel, and SPSS/PASW. Table 1 summarizes the total rating results for each of the roles. Illustrated are the percentages of each rating (extensively to never) along with combined results for extensive/frequent and rarely/never. Means, standard deviations, frequencies and range scores for each role are also provided.

As shown, five of the six roles were reported by respondents to be implemented extensively to frequently, with Role 4 (Differentiation) being the most extensively employed. Role 2 has an overall rating of frequently to rarely and was the least emphasized role. However, although lower than the other five roles, 58\% indicated that they extensively/frequently implemented Role 2 . The following Tables (2-7) illustrate the means and standard deviations for each subskill within each role, listed from most to least implemented. Also provided is each of the Probing Questions to which practitioners responded in their consideration of rating the subskill (1 = Extensively; 2 = Frequently; 3 = Rarely; 4 = Never). 
Table 1. Percentage breakdown of rating classifications for each role

\begin{tabular}{|c|c|c|c|c|c|c|}
\hline Rating & Role 1 & Role 2 & Role 3 & Role 4 & Role 5 & Role 6 \\
\hline Extensively & $27 \%$ & $20 \%$ & $28 \%$ & $38 \%$ & $23 \%$ & $26 \%$ \\
\hline Frequently & $53 \%$ & $38 \%$ & $43 \%$ & $50 \%$ & $49 \%$ & $52 \%$ \\
\hline Rarely & $16 \%$ & $24 \%$ & $21 \%$ & $10 \%$ & $24 \%$ & $18 \%$ \\
\hline Never & $4 \%$ & $18 \%$ & $7 \%$ & $2 \%$ & $5 \%$ & $4 \%$ \\
\hline Total & $100 \%$ & $100 \%$ & $100 \%$ & $100 \%$ & $100 \%$ & $100 \%$ \\
\hline Extensively/Frequently & $80 \%$ & $58 \%$ & $71 \%$ & $88 \%$ & $72 \%$ & $78 \%$ \\
\hline Rarely/Never & $20 \%$ & $42 \%$ & $29 \%$ & $12 \%$ & $28 \%$ & $22 \%$ \\
\hline Mean & 1.96 & 2.34 & 2.07 & 1.77 & 2.10 & 2.00 \\
\hline SD & .77 & .98 & .88 & .71 & .80 & .78 \\
\hline Range & $1.46-2.53$ & $1.27-3.16$ & $1.73-2.57$ & $1.41-2.35$ & $1.61-2.39$ & $1.62-2.63$ \\
\hline
\end{tabular}

Note: Means between 1 and 2 indicate the skill being used extensively/frequently, between 2 and 3 frequently/rarely, and between 3 and 4 rarely/never

Role 1: Data-Driven Decision Maker

Role 2: Implementer of Evidence-Based Practice

Role 3: Implementer of socio-emotional and behavioral supports

Role 4: Differentiator of Instruction

Role 5: Implementer of instructional/assessment accommodations

Role 6: Collaborator

Table 2. Role 1: Data-Driven Decision Maker (13 subskills)

\begin{tabular}{|l|l|l|}
\hline $\begin{array}{l}\text { Probing Survey Question: To what extent do you consider data associated with each skill area when making instructional adjustments or other } \\
\text { educational decisions? }\end{array}$ & Mean \\
\hline & 1.46 \\
\hline Progress Monitoring & 1.71 \\
\hline Curriculum-based measurement & 1.79 \\
\hline Performance-based assessment & .53 \\
\hline Validity of scores & .72 \\
\hline Assessment fidelity & .88 \\
\hline Rate of progress & .75 \\
\hline Reliability of scores & .82 \\
\hline Universal screening & 1.88 \\
\hline Graphs/Charts of learner progress & .72 \\
\hline Systematic direct observation & .76 \\
\hline Gap analysis & .79 \\
\hline Dynamic assessment & .92 \\
\hline Functional behavioral assessment & 1.94 \\
\hline
\end{tabular}

Note: Means between 1 and 2 indicate skill being used extensively/frequently, between 2 and 3 frequently/rarely, and between 3 and 4 rarely/never

Table 3. Role 2: Implementer of Evidence-Based Practice (30 subskills)

\begin{tabular}{|c|c|c|}
\hline & Mean & $S D$ \\
\hline Scaffolding & 1.27 & 0.45 \\
\hline Direct instruction & 1.35 & 0.52 \\
\hline Graphic organizers & 1.47 & 0.61 \\
\hline Sheltered instruction & 1.53 & 0.82 \\
\hline Progress monitoring with fidelity & 1.66 & 0.59 \\
\hline Integrating higher order thinking methods & 1.71 & 0.67 \\
\hline Self-questioning & 1.98 & 0.61 \\
\hline Determination of fidelity of implementation of interventions & 1.98 & 0.75 \\
\hline Peer-mediated instruction/Cooperative learning & 2.08 & 0.79 \\
\hline Task analysis & 2.10 & 0.75 \\
\hline Language experience approach & 2.14 & 0.77 \\
\hline Mastery learning & 2.24 & 0.80 \\
\hline Literature response groups & 2.30 & 0.96 \\
\hline Reading response journal & 2.32 & 0.97 \\
\hline Self-regulated learning & 2.32 & 0.65 \\
\hline Reciprocal teaching & 2.39 & 0.72 \\
\hline Peer revising strategy - Writing & 2.52 & 0.78 \\
\hline Read naturally strategy & 2.53 & 0.88 \\
\hline Precision teaching & 2.62 & 0.98 \\
\hline Schema-based instruction (SBI) & 2.63 & 0.87 \\
\hline Class-wide peer tutoring (CWPT) & 2.69 & 0.80 \\
\hline Collaborative strategic reading (CSR) & 2.74 & 1.02 \\
\hline Focus correction areas writing strategy & 2.80 & 0.97 \\
\hline Readers' theatre & 2.80 & 0.82 \\
\hline Cognitive guided instruction (CGI) & 2.88 & 0.85 \\
\hline Fernald multisensory approach & 2.94 & 0.83 \\
\hline Peer assisted learning strategies (PALS) -Reading & 2.96 & 0.98 \\
\hline Incremental rehearsal & 3.14 & 0.90 \\
\hline Peer assisted learning strategies (PALS) - Mathematics & 3.16 & 0.97 \\
\hline Concrete-semiconcrete-abstract math process (CSA) & 3.16 & 0.98 \\
\hline
\end{tabular}

Note: Means between 1 and 2 indicate the skill being used extensively/frequently, between 2 and 3 frequently/rarely, and between 3 and 4 rarely/never 
Table 4. Role 3: Implementer of socio-emotional and behavioral supports (15 subskills)

Probing Survey Question: To what extent do you use each skill area when implementing positive behavioral interventions and supports?

\begin{tabular}{|l|l|l|}
\hline \multicolumn{2}{|l|}{ Probing Survey Question: To what extent do you use each skill area when implementing positive behavioral interventions and supports? } \\
\hline Clearly articulated transition procedures for changing activities & Mean & SD \\
\hline Proximity control & 1.73 & 0.66 \\
\hline Culturally responsive class management & 1.74 & 0.80 \\
\hline School-wide behavioral program & 1.75 & 0.65 \\
\hline Progressive reinforcements & 1.78 & 0.94 \\
\hline Student self-monitoring & 1.96 & 0.88 \\
\hline Behavior replacement strategies & 2.00 & 0.59 \\
\hline Social skills development programs/curricula & 2.04 & 0.77 \\
\hline Planned ignoring & 2.10 \\
\hline Antecedent-Behavior-Consequence (ABC) & 2.10 & 0.89 \\
\hline Reducing aggressive/impulsive behaviors & 2.16 & 0.91 \\
\hline Behavior support teams & 2.16 & 0.92 \\
\hline Functional behavioral assessment & 2.18 \\
\hline Applied Behavior Analysis (ABA) & 0.87 \\
\hline Functional skills assessment & 2.35 & 0.94 \\
\hline Note: Mean betwn & 0.88 \\
\hline
\end{tabular}

Note: Means between 1 and 2 indicate the skill being used extensively/frequently, between 2 and 3 frequently/rarely, and between 3 and 4 rarely/never

Table 5. Role 4: Differentiator of instruction (17 subskills)

Probing Survey Question: To what extent do you use each skill area when differentiating classroom/instructional management?

\begin{tabular}{|c|c|c|}
\hline & Mean & SD \\
\hline Flexible use of small and cooperative groupings & 1.41 & 0.57 \\
\hline Positive reinforcements and rewards & 1.43 & 0.50 \\
\hline Procedures for activating prior knowledge & 1.43 & 0.50 \\
\hline Culturally responsive strategies & 1.53 & 0.70 \\
\hline Regular monitoring of learner progress & 1.55 & 0.54 \\
\hline Guided practice & 1.57 & 0.53 \\
\hline Effective teacher time management & 1.69 & 0.61 \\
\hline Creating authentic learning tasks & 1.71 & 0.60 \\
\hline Effective student time management & 1.80 & 0.63 \\
\hline Teaching study skills/learning strategies & 1.82 & 0.58 \\
\hline Student self-management/organization skills & 1.86 & 0.63 \\
\hline Balancing teaching styles with student preferred learning styles & 1.88 & 0.62 \\
\hline Multiple intelligences in instruction & 1.92 & 0.68 \\
\hline Balancing active/passive learning tasks & 1.92 & 0.59 \\
\hline Learning centers & 2.04 & 1.03 \\
\hline Coordinate RTI tiers 1 and 2 instruction & 2.14 & 0.93 \\
\hline Replacement behavior development & 2.35 & 0.84 \\
\hline
\end{tabular}

Note: Means between 1 and 2 indicate the skill being used extensively/frequently, between 2 and 3 frequently/rarely, and between 3 and 4 rarely/never

Table 6. Role 5: Implementer of instructional/assessment accommodations (10 subskills)

Probing Survey Question: To what extent do you use each of the following when making instructional and assessment accommodations?

Presentation (instruction): adjusting manner in which instructional material is presented

Response (instruction): providing alternate response formats to obtain more accurate instructional results

Presentation (assessment): adjusting manner in which assessment material is presented

Response (assessment): providing alternate response formats to obtain more accurate assessment results

Time (instruction): adjusting block of time (e.g. 2 twenty minute blocks instead of 1 forty minute block) for completing instructional

tasks

Time (assessment): adjusting block of time (e.g. 2 twenty minute blocks instead of 1 forty minute block) for completing assessment

tasks

Scheduling (assessment): adjusting time of day (morning vs. afternoon) for completing assessment tasks

Setting (instruction): changing the location where learners complete instructional tasks

Scheduling (instruction): adjusting time of day (morning vs. afternoon) for completing instructional tasks

Setting (assessment): changing the location where learners complete assessment tasks

\begin{tabular}{|l|l|l|}
\hline Mean & SD \\
\hline & 1.61 & 0.56 \\
\hline & 1.76 & 0.58 \\
\hline 1.94 & 0.67 \\
\hline & 2.00 & 0.69 \\
\hline 2.08 & 0.79 \\
\hline & 2.12 & 0.68 \\
\hline & 2.33 & 0.78 \\
\hline 2.37 & 0.88 \\
\hline 2.39 & 0.93 \\
\hline 2.39 & 0.86 \\
\hline
\end{tabular}

Note: Means between 1 and 2 indicate the skill being used extensively/frequently, between 2 and 3 frequently/rarely, and between 3 and 4 rarely/never

Table 7. Role 6: Collaborator (15 subskills)

Probing Survey Question: To what extent do you use/apply each skill when collaborating?

Culturally responsive teaching

Modeling effective strategies for meeting needs of students with disabilities

Knowledge/understanding of the Individuals With Disabilities Education Improvement Act of 2004 (IDEIA)

Knowledge of district special education referral and assessment process within RTI models

Consulting strategies

Components of RTI models (e.g. 3-tiered instruction, fidelity)

Team development strategies

Supports to parents in special education process (e.g. referral, eligibility, IEP)

Process for keeping parents informed of child's progress within the RTI model

School-level RTI team support

Parent-school-community partnerships

Grade-level RTI team support

Peer coaching

Effective strategies for creating change

Co-teaching

Note: Means between 1 and 2 indicate the skill being used extensively/frequently, between 2 and 3 frequently/rarely, and between 3 and 4 rarely/never 
In addition, select correlations were conducted to determine significance of ratings with year the MA and endorsement completed, type of education position (i.e., special or general class educator), and length of time working within an RTI model. No correlations were significant.

\section{Discussion}

This survey research project was designed to gather information to respond to one research question: To what extent do practitioners trained as special educators report engaging in six key roles, and associated subskills, in their implementation of an RTI Model? Overall, all six roles were reported to be implemented extensively or frequently in this rank order:

Role 4: Differentiator of Instruction

Role 1: Data-Driven Decision Maker

Role 6: Collaborator

Role 3: Implementation of socio-emotional and behavioral supports

Role 5: Implementer of instructional/assessment accommodations

Role 2: Implementer of Evidence-Based Practice

Table 8 provides a rank ordering of the top 30 subskills, across all six roles, engaged in as reported by practitioners in their implementation of an RTI model.

Table 8. Rank Order of Top 30 Role Subskills Reported as Extensively and Frequently Implemented

\begin{tabular}{|c|c|}
\hline 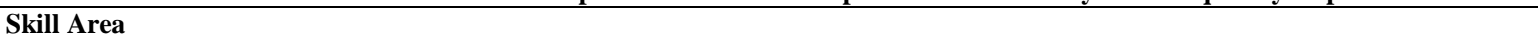 & Role \\
\hline Scaffolding & Role 2 \\
\hline Direct instruction & Role 2 \\
\hline Flexible use of small and cooperative groupings & Role 4 \\
\hline Positive reinforcements and rewards & Role 4 \\
\hline Procedures for activating prior knowledge & Role 4 \\
\hline Progress monitoring & Role 1 \\
\hline Graphic organizers & Role 2 \\
\hline Sheltered instruction & Role 2 \\
\hline Culturally responsive strategies & Role 4 \\
\hline Regular monitoring of learner progress & Role 4 \\
\hline Guided practice & Role 4 \\
\hline Accommodation: Presentation (instruction) & Role 5 \\
\hline Culturally responsive teaching & Role 6 \\
\hline Progress monitoring with fidelity & Role 2 \\
\hline Effective teacher time management & Role 4 \\
\hline Curriculum-based measurement & Role 1 \\
\hline Integrating higher order thinking methods & Role 2 \\
\hline Creating authentic learning tasks & Role 4 \\
\hline Modeling effective strategies for meeting needs of students with disabilities & Role 6 \\
\hline Clearly articulated transition procedures for changing activities Knowledge/understanding of the Individuals With Disabilities Education & Role 3 \\
\hline Improvement Act of 2004 (IDEIA) & Role 6 \\
\hline Culturally responsive class management & Role 3 \\
\hline Proximity control & Role 3 \\
\hline Response (instruction): providing alternate response formats to obtain more accurate instructional results & Role 5 \\
\hline Performance-based assessment & Role 1 \\
\hline Effective student time management & Role 4 \\
\hline School-wide behavioral program & Role 3 \\
\hline Knowledge of district special education referral and assessment process within RTI models & Role 6 \\
\hline Teaching study skills/learning strategies & Role 4 \\
\hline Student self-management/organization skills & Role 4 \\
\hline
\end{tabular}

As shown, highly qualified special educators report using various subskills representing all six roles to successfully deliver instruction and assessment in an RTI model. Specific subskill responses provide additional insight into how practitioners perceive themselves engaged in implementing the six roles.

\subsection{Subskill Analysis: Data-Driven Decision Maker}

Progress monitoring, curriculum-based measurement and performance-based assessment were the most frequently reported skills in the role of Data-driven Decision Maker. This finding is highly encouraging as both progress monitoring and the use of curriculum-based measurement are fundamental to the success of any RTI model. Conversely, although identified as implemented regularly, systematic direct observation, gap analysis, dynamic assessment, and functional behavioral assessment are four skill areas least implemented in this role. Gap analysis is essential to determine the necessary rate of progress needed to achieve at benchmark and develop a realistic plan to close the gap. Functional behavioral assessment is an essential skill for addressing socialemotional and behavior needs of learners within RTI models. Additionally, implementing systematic observations and dynamic assessment contributes significantly to the role of data based decision-making. Special education training and professional development should be certain to further emphasize these skills to best develop practitioners' abilities to efficiently and effectively implement data-based decision making within RTI, while also continuing to support the more frequently used progress monitoring and curriculum-and performance-based measurement skills.

\subsection{Subskill Analysis: Implementer of Evidence-Based Practice}

The practices of scaffolding, direct instruction, graphic organizers, sheltered instruction, integrating higher order thinking methods and self-questioning were among the most extensively or frequently reportedly used evidencebased practices. This finding supports the notion that 
many educators may use these practices because each: 1) is applicable in variety of content areas, 2) contains more flexibility in implementation rather than strict adherence to a set of steps or procedures, and 3) is more easily incorporated into daily teaching and learning. Other interventions reportedly used on a frequent basis include mastery learning, reciprocal teaching, self-regulated learning, peer-mediated instruction/cooperative learning, and language experience approach. Each of these requires more extensive amounts of training, which may account for the somewhat less reported extensive use than the others previously identified. Therefore, a variety of interventions and practices appear to be used within an RTI model by those who have received training in special education.

However, several other interventions found to be effective, based on evidence, are reportedly used less frequently. These include peer-assisted learning strategies (PALS) in both reading and mathematics, class-wide peer tutoring, schema-based instruction, or cognitive guided instruction. This finding is concerning in that each of these interventions is shown to be effective and appropriate for use in providing core and/or supplemental instruction within an RTI model. Extensive training is required or recommended to successfully use these interventions in the classroom and this may be a barrier to their more frequent uses. However, given their importance in the overall implementation of multi-tiered instruction within an RTI model, special education training and professional development should include necessary time and support to assist practitioners to acquire the knowledge and skills needed to employ these instructional subskills to best fulfill the role of implementer of evidence-based practice.

\subsection{Subskill Analysis: Implementer of Socio- Emotional and Behavioral Supports}

Practitioners self-reported that a variety socioemotional and behavioral supports are used regularly including: articulating the process for changing activities or making transitions; considering learners' cultural needs in class management; and using proximity control, progressive reinforcement, behavior replacement strategies and self-monitoring in teaching and learning. Also, a school-wide behavioral program is reported as extensively implemented by most practitioners. This is a positive finding as each of these important skills serve to provide a comprehensive approach to meeting emotional and behavioral needs in the classroom. However, although each of these is essential to assuming the role of implementer of emotional/behavioral supports, several other key practices may not be as frequently used. These include applied behavior analysis, functional skills assessment, functional behavior assessment, and use of behavior support teams. Use of each of these is supported by extensive research and should be emphasized in special education training or professional development, to further improve the role of implementer of socioemotional/behavioral supports within an RTI model.

\subsection{Subskill Analysis: Differentiator of instruction}

Based on practitioners' reporting differentiation is the most extensively implemented role with all associated subskills being employed on an extensive or highly frequent basis. Skills reported as most extensively used to differentiate instruction include: 1) small and cooperative groupings, 2) application of positive reinforcements, 3) activation of prior knowledge activities, 4) culturally responsive teaching, 5) guided practice, and 6) regular monitoring of learner progress to inform instruction. Skills reportedly implemented frequently or slightly less extensively included development of replacement behaviors, use of learning centers, and the coordination of Tiers 1 and 2 instruction. This finding is highly encouraging since differentiation of instruction is essential to providing all learners sufficient and appropriate opportunities to learn within an RTI model, where a 'one size fits all' philosophy rarely succeeds at addressing all learner needs. As educators conduct trainings to prepare special education practitioners for their all-important role of differentiator of instruction, each of these subskills should receive sufficient attention. This includes making certain that instruction in Tiers 1 and 2 are connected, thereby ensuring that Tier 2 instruction supports, rather than replaces, Tier 1 teaching and learning.

\subsection{Subskill Analysis: Implementer of Instructional/Assessment Accommodations}

The role of making instructional and assessment accommodations is reported by highly qualified special educators as 'frequently' implemented in teaching and learning within RTI. While encouraging, this finding suggests that more effort to prepare practitioners for this role is warranted to better achieve 'extensive' implementation. It is important to recognize that instructional adjustments directly reflect sufficient opportunities to learn, and that accommodations in assessment may apply to both universal screening and progress monitoring tasks, in addition to diagnostic and end-of-year performance assessments. Specifically, accommodations to presentation and mode of response appear to be employed more frequently in both assessment and instructional situations, while accommodations to address time, scheduling and setting needs in assessment and instruction are less frequently implemented. This finding highlights the need for special education training and professional development to continue efforts in preparing practitioners for this essential role of accommodating needs in both instruction and assessment, especially when considering scheduling and setting needs.

\subsection{Subskill Analysis: Collaborator}

Practitioners who are highly qualified as special educators indicated that they engage in their role as collaborator on a frequent basis, with the skills of culturally responsive teaching, team development strategies, consultation, familiarity with the main components of RTI, modeling teaching strategies, providing supports to parents, and using knowledge about IDEA and district special education provisions being the most widely employed. Although this role is viewed as 'frequently' implemented it ranked third of the six roles, which leaves much room for additional application by practitioners in RTI models. Specifically, several key collaboration skills were identified as less frequently used including: 1) co-teaching, 2) peer coaching, 3) providing 
support to grade level teams, 4) using strategies for creating effective change, and 5) utilizing parent-schoolcommunity partnerships. Given the complexities associated with implementing a comprehensive, school-wide RTI model where both academic and social/behavioral aspects of learning are addressed, the need for collaboration increases exponentially. Additionally, the many diverse needs students bring to today's classrooms (e.g., second language needs, cultural differences, wide ranges of reading levels, varied experiential backgrounds, etc.), further highlight the need for increased collaboration efforts among all educators. As special education training and professional development activities are planned and implemented, this crucial role must continue to be emphasized in order to sufficiently implement an RTI model.

\section{Limitations, Conclusions Recommendations}

\subsection{Study Limitations}

This study examined the self-reported views of highly qualified practitioners in special education who completed their MA degree and endorsement at a large research university in a mountain western state in the United States. Actual educational settings were not observed to confirm the practitioners' responses and therefore are only reflective of their perceptions of how they implement each role within an RTI model in their schools. Also, as previously discussed, while the six roles and associated 100 subskills are literature based along with pilot feedback, they are not designed to be all-inclusive, and therefore other roles and skills may be considered important. Results should be considered relative to these potential limitations while also recognizing several generalizable elements: 1) a high response rate was obtained, 2) the university program completed by the respondents is state and nationally accredited meeting each of the professional standards set forth by the Council for Exceptional Children (CEC), and 3) the courses and experiences of the respondents reflect those of other nationally recognized graduate level teacher training MA and endorsement programs.

\subsection{Conclusions}

Results from this research inform educators who engage in practitioner training in special education through both university teacher training programs and school district professional development. Below are several summary conclusions drawn from the feedback provide by highly qualified special educators:

1. All six roles are reported as implemented on a frequent or extensive basis in RTI models;

2. Differentiator of Instruction and Data-Driven Decision Maker are reported as the most extensively implemented roles, while Implementer of Evidence-Based Practice is reported as the least implemented of the six roles investigated;

3. Progress monitoring and curriculum-based measurement are reported as two of the most extensively employed skills in implementing the role of Data-Driven Decision Making;
4. Several important evidence-based and promising practices are reported as frequently used in RTI models including scaffolding, sheltered instruction, direct instruction, graphic organizers, self-regulated learning, task analysis, language experience approach, and selfquestioning;

5. Interventions that require more extensive training such as PALS, class-wide peer tutoring, cognitive guided instruction and schema-based instruction are reported as less frequently used;

6. Selected skills across all the different roles that are reported as infrequently or rarely employed include PALS, functional behavioral assessment, co-teaching, replacement behavior development, applied behavior analysis, functional skills assessment, and setting accommodations for assessment;

7. Practitioners appear to engage in the role of Collaborator on a frequent basis employing the skills of modeling, consulting and cultural responsiveness most frequently; and,

8. Adherence to school-wide behavior programs and culturally responsive classroom management are reported as frequent occurrences to meet the socio-emotional and behavior needs of learners within an RTI model.

\subsection{Recommendations}

Based on the findings and conclusions, the following recommendations are suggested for special education training programs and professional development activities focusing on developing the six roles:

1. Provide greater emphasis on those skills found to be evidence-based yet less frequently used to strengthen the role of Implementer of Evidence-Based Practice, specifically PALS, schema-based instruction, class-wide peer tutoring, concrete-semiconcrete-abstract math process, and cognitive guided instruction;

2. Generate creative ways to assist practitioners to increase their role as a Collaborator through strategic uses of instructional time and resources facilitated by peer coaching, modeling and co-teaching;

3. Continue to strengthen the role of Implementer of Socio-Emotional and Behavioral Supports with greater emphasis on training to use functional behavioral assessment, behavior support teams, and applied behavioral analysis;

4. Build on the strengths of the implementation of the role, Differentiator of Instruction, through continued emphasis on the various differentiation subskills currently being employed especially guided practice, culturally responsive teaching, activating prior knowledge and creating authentic learning tasks;

5. Strengthen the role of Implementer of Instructional/Assessment Accommodations by assisting practitioners to know that accommodations are an essential part of instruction and assessment within an RTI model, stressing that these are implemented to: 1) provide sufficient opportunities to learn, and 2) demonstrate learning resulting from those opportunities; and,

6. Continue to strengthen the cornerstone of any RTI model (i.e., data usage) through more complete development of the Data-Driven Decision Making role including the skills of progress monitoring, curriculumbased measurement, functional behavioral assessment, and 
ensuring that screening and monitoring scores are valid and reliable to appropriately reflect learner progress.

\section{References}

[1] Alberto, P.A. \& Troutman, A.C. (2012). Applied Behavior Analysis for Teachers (9th Edition). Boston, MA: Pearson.

[2] Allen, R. V. (1976). Language experiences in communication. Boston, MA: Houghton Mifflin.

[3] Cook, B.G. \& Cook, S.C. (2011). Thinking and Communicating Clearly About Evidence-based Practices in Special Education. Division of Research, CEC.

[4] Colorado Department of Education (CDE) (2008). Response to intervention (RtI): A practitioner's guide to implementation. Denver, CO: Colorado Department of Education. Author.

[5] Council for Exceptional Children. (2007). Position on response to intervention (RTI): The unique role of special education and special educators. Washington, DC: Council for Exceptional Children.

[6] Council for Exceptional Children. (2009). What every special educator must know: The international standards for the preparation and certification of special education teachers (6th ed.). Arlington, VA: Council for Exceptional Children.

[7] Cummings. K.D., Atkins, T., Allison, R., \& Cole, C. (2008). Response to intervention: Investigating the new role of special educators. Teaching Exceptional Children, 40(4), 8.

[8] Dettmer, P., Knackendoffel, A.P., \& Thurston, L.P. (2012) Collaboration, Consultation, and Teamwork for Students with Special Needs, ( $7^{\text {th }}$ Edition). Boston, MA: Pearson.

[9] Fisher, D., Frey, N., \& Thousand, J. (Winter 2003). What do special educators need to know and be prepared to do for inclusive schooling to work? Teacher Education and Special Education: The Journal of the Teacher Education Division of the Council for Exceptional Children, 26(1), 42-50.

[10] Friend, M.D. and Cook, L. (2012). Interactions: Collaboration Skills for School Professionals ( $7^{\text {th }}$ Edition), Boston, MA: Pearson.

[11] Fuchs, D., \& Deshler, D. D. (2007). What we need to know about responsiveness to intervention (and shouldn't be afraid to ask). Learning Disabilities Research \& Practice, 22(2), 129-136.

[12] Fuchs, D., \& Fuchs, L. S. (2006). Introduction to response to intervention: What, why, and how valid is it? Reading Research Quarterly, 41(1), pp. 93-99.

[13] Fuchs, L. S., \& Fuchs, D. (2009). On the importance of a unified model of responsiveness to intervention. Child Development Perspectives, 3(1), 41-43.

[14] Fuchs, D., Fuchs, L. S., \& Burish, P. (2000). Peer-assisted learning strategies: An evidence-based practice to promote reading achievement. Learning Disabilities Research and Practice,15, 8591.

[15] Gay, G. (2010). Culturally Responsive Teaching: Theory, Research, and Practice, 2nd Edition. New York: Teacher's College Press.

[16] Gravois, T.A., Knotek, S., \& Babinski, L. M. (2002). Educating Practitioners as Consultants: Development and Implementation of the Instructional Consultation Team Consortium. Journal of Educational and Psychological Consultation, 13(1), pp. 113-132.

[17] Greenwood, C. R., Arreaga-Mayer, C., Utley, C. A., Gavin, K.M., \& Terry, B. J. (2001). Class Wide Peer Tutoring Learning Management system: Applications with elementary-level English language learners. Remedial and Special Education, 22, 34-47.

[18] Hall, S. L. (2008). A principal's guide: Implementing response to intervention. Thousand Oaks, CA; Sage.

[19] Hoover, J. J. (2009). Differentiating learning differences from disabilities. Columbus, $\mathrm{OH}$ : Pearson.

[20] Hoover, J. J., Baca, L. M., Wexler-Love, E., \& Saenz, L. (2008). National Implementation of Response to Intervention (RTI): Research Summary. University of Colorado, Boulder-BUENO Center. Retrieved September 1, 2009, from the National Association of State Directors of Special Education (NASDSE). Web site: www.nasdse.org

[21] Hoover, J. J., \& Patton, J. R. (2008). The role of special educators in a multitiered instructional system. Intervention in School and Clinic, 43(4), 195-202.

[22] Jitendra, A., K. (2008). Using schema-based instruction to make appropriate sense of word problems. Perspectives on Language and Literacy, Spring, pp. 20-24.
[23] Katsiyannis, A., Zhang, D., Ryan, J.B., \& Jones, J. (2007). Highstakes testing and students with disabilities: challenges and promises. Journal of Disability Policy Studies Winter 2007 18: 160-167.

[24] Kim, A-H, Vaughn, S., Wanzek, J., \& Wei, S. (2004). Graphic organizers and their effects on the reading comprehension of students with ld: a synthesis of research. Journal of Learning Disabilities. 37(2), 105-118.

[25] Knotek. (2005). Sustaining RTI through consultee-centered consultation. California School Psychologist, 10, 93.

[26] Linan-Thompson, S., Vaughn, S., Prater, K., \& Cirino, P. T. (September/October 2006). The response to intervention of English language learners at risk for reading problems. Journal of Learning Disabilities, 39(5), 390-398.

[27] McConnell, M. (2001) Functional behavioral assessment. Denver: Love Publishing Co.

[28] Mitchell, B. B. (2011). Examining the role of the special educator in a response to intervention model. (Unpublished $\mathrm{PhD}$.). University of Kansas.

[29] Montague, M., \& Dietz, S. (2009). Evaluating the Evidence Base for Cognitive Strategy Instruction and Mathematical Problem Solving. Exceptional Children, 75 (3), pp. 285-302.

[30] National Association of School Psychologists. (2006). New roles in response to intervention: Creating Success for Schools and Children Bethesda, MD: Retrieved from:

http://www.nasponline.org/advocacy/rtifactsheets.aspx on September 11, 2010.

[31] National Research Center on Learning Disabilities (NRCLD) (2006). A tiered service delivery model. Retrieved February 4, 2013 from

http://www.nrcld.org/rti_manual/pages/RTIManualSection3.pdf.

[32] Orosco, M. J. (2004). Accommodations in assessment and instruction to meet special needs. In Current Issues in Special Education: Meeting Diverse Needs in the Twenty -First Century. Boulder: Bueno Center for Multicultural Education.

[33] Palenchar, L. M. (2012). A study of West Virginia elementary special education teachers' roles, responsibilities, and practices within a multitiered instructional support system: Implications for policy and practice. (Unpublished Dissertation). Marshall University, WV.

[34] Palincsar, A. S., \& Brown, A. L. (1984). The reciprocal teaching of comprehension fostering and comprehension-monitoring activities. Cognition and Instruction, 1, 117-175.

[35] Peterson, J. M., \& Hittie, M. M. (2010). Inclusive teaching: The journey towards effective schools for all learners. Boston, MA: Pearson.

[36] Salend, S. J. (2010). Creating inclusive classrooms: Effective and reflective practices. Upper Saddle River, NJ: Pearson Education.

[37] Stuart, S.K. \& Rinaldi, C. (2009) A collaborative planning framework for teachers implementing tiered instruction. Teaching Exceptional Children, 42(2), 52-57.

[38] Sugai, G. School-Wide Positive Behavior Support and Response to Intervention. Retrieved 1/25/2013 from RTI Action Network Website: rtinetwork.org.

[39] Sugai, G., Horner, R. H., Dunlap, G., Hieneman, M., Lewis, T. J., Nelson, C. M., Scott, T., Liaupsin, C., Sailor, W., Turnbull, A. P., Turnbull, H. R. III, Wickham, D., Reuf, M., \& Wilcox, B. (2000). Applying positive behavioral support and functional behavioral assessments in schools. Journal of Positive Behavioral Interventions, 2, 131-143.

[40] Swanson, E., Solis, M., Ciullo, S., \& McKenna, J. W. (2012). Special education teachers' perceptions and instructional practices in response to intervention implementation. Learning Disability Quarterly, 35(2), 115-126.

[41] Thurlow, M.L., Elliott, J.L., \& Ysseldyke, J.E. (2003). Testing students with disabilities: Practical strategies for complying with district and state requirements (2nd ed.). Thousand Oaks, CA: Corwin Press.

[42] Tomlinson, C.A. (1999). The Differentiated Classroom: Responding to the Needs of All Learners. Boston, MA: Pearson.

[43] Tomlinson, C.A. \& Imbeau, M.B. (2010). Leading and Managing a Differentiated Classroom. Alexandria,VA: ASCD.

[44] Vaughn, S. (2003, December). How Many Tiers Are Needed for Response to Intervention to Achieve Acceptable Prevention Outcomes? Paper presented at The National Research Center on Learning Disabilities Responsiveness-to-Intervention Symposium, Kansas City, MO. 
[45] Vaughn, S., \& Fuchs, L. S. (2003). Redefining learning disabilities as inadequate response to instruction: The promise and potential problems. Learning Disabilities Research \& Practice, 18(3), 137146.

[46] Vaughn, S., \& Linan-Thompson, S. (2003). What is special about special education for students with learning disabilities? The Journal of Special Education, 37(3), 140-147.
[47] Werts, M. G., Lambert, M., \& Carpenter, E. (2009). What special education directors say about RTI. Learning Disability Quarterly, 32(4), 245-254.

[48] Western Interstate Commission on Higher Education. Promising practices. Retrieved 1/15/2013 from http://www.wiche.edu/archive/mh/promisingPractices. Author. 